\title{
Artificial reactor containing polymeric bilayer architectures for the formation of self-controlled tandem catalytic-ability
}

\author{
Z. Xia, W. Wei, M. Zhu, S. Wu, X. Shen, S. $L i^{*}$ \\ Research School of Polymeric Materials, School of Materials Science \& Engineering, Jiangsu University, \\ 212013 Zhenjiang, China
}

Received 7 May 2019; accepted in revised form 17 July 2019

\begin{abstract}
For addressing the present challenges in tandem catalysts, an artificial reactor capable of self-controlled tandem catalytic-ability was reported in this study. Inspired from the polymeric properties and divisional isolation for tandem processes in natural biological systems, this reactor was fabricated with polymeric bilayer architectures. The first layer was made of a reactive shape memory polymer that contained thermosensitive polymeric networks, acting as a molecular switch for the occurrence of the precedent hydrolysis of bis(4-nitrophenyl)carbonate. The second layer consisted of a molecularly-imprinted polymer and encapsulated Ag nanoparticles, allowing access to the succeeding reduction of the intermediate 4-nitrophenol. In a cooperative way, the polymeric bilayer architectures planted in this artificial reactor led to the formation of self-controlled tandem catalytic-ability. The suggested design for this artificial reactor shares a promising prospect with the struggling tandem catalysts, which leads to opportunities to develop controllable tandem processes.
\end{abstract}

Keywords: smart polymers, bilayer architectures, artificial reactors, self-controlled catalytic ability

\section{Introduction}

The development of self-controlled tandem catalysts remains an attractive subject in chemical synthesis, regardless of the technological challenges [1-3]. The use of self-controlled tandem catalysts in chemical synthesis would allow the ongoing tandem reactions to run in a controllable and tunable way, endowing the systems with catalytic one-pot ability [4, 5]. This privilege often arises from the careful control of the structure-activity relationship at the undergoing catalysts (such as the adoption of smart hydrogels [6], functional microspheres [7] and hierarchical structures [8]), which leads to a restriction on either the substrate channeling or access to the catalytic sites in these catalysts. In this way, the use of self-controlled catalysts leads to the occurrence of self-controlled catalytic ability. Nonetheless, the practical applications of self-controlled tandem catalysts have been not remarkable over the years, in contrast to simple catalysts which have shown diverse applications in industry, agriculture, aerospace, military, etc $[9,10]$. An important reason behind this may be due to the complexity of tandem mechanisms and the diversity of tandem processes, along with the potential competition of different catalytic sites. It is therefore not realistic to achieve the desired self-controlled tandem catalysts by simply copying the self-controlled patterns from simple catalysts. As such, new protocols capable of meeting the self-controlling requirements in tandem catalysts are required.

Nature has been mankind's tutor for knowledge. Natural biological systems (mainly active entities, such as the cells $[11,12]$ ), as catalytic reactors, often have the abilities to meet self-controlled tandem processes (typically, catalytic hydrolysis and redox processes [13]), since these abilities are essential for 
their survival. The main clues behind this can be related to the constituent proteins in these natural reactors [14], which are often polymeric and 'soft' in nature and tolerate an 'arbitrary' piling-up of the morphology and structures. Such characteristics would allow the natural biological systems to divisionally isolate and control the tandem processes and even allow different reactions to run in different 'compartments' [15]. In this way, natural biological systems, as catalytic reactors, show the fine self-controlled ability to meet complicated reaction conditions and key challenges for survival.

Inspired by the principle in nature, here, we aim at meeting the present challenges in tandem catalysts by reporting an artificial reactor which was capable of self-controlled tandem catalytic- ability. By borrowing the polymeric 'soft' properties and divisional concept from natural systems, this artificial reactor was fabricated with polymeric bilayer architectures that allowed finely controlling the tandem processes and accordingly avoided the potential competition of different catalytic sites. As outlined in Figure 1, the first layer, which may be responsible for the occurrence of a precedent reaction (such as catalytic hydrolysis), consisted of a reactive shape-memory polymer made of poly(2-acrylamido-2-methylpropanesulfonic acid-co-2-nonenoic acid) (PAMD) that contained thermosensitive polymeric networks [16]. The second layer, which provided access to the succeeding reaction, was made of an intermediate-imprinted poly(acrylamide) (PAA) hydrogel and encapsulated Ag nanoparticles. In a cooperative way, the bilayer architectures would enable this reactor to have selfcontrolled tandem catalytic-ability. Specifically, at relatively low temperatures (lower than the transition temperature of PAMD), the 'closed' polymeric networks in the first layer may inhibit access to the first layer [17] and accordingly shut down the catalytic process. In contrast, at higher temperatures (higher than the transition temperature of PAMD), the access to the first layer may become open in response to the activation of the polymeric networks, which accordingly led to the occurrence of the precedent reaction (due to the acidic sites within the first layer). Following this, the second layer would provide access to the succeeding reaction for the intermediate (and accordingly excluded access for other molecules due to the molecular recognition properties in the imprinted hydrogel). In this way, the artificial reactor led to the formation of self-controlled tandem catalytic-ability.

To that end, bis(4-nitrophenyl)carbonate (BNPC) and 4-nitrophenol (NP) were elaborately selected as

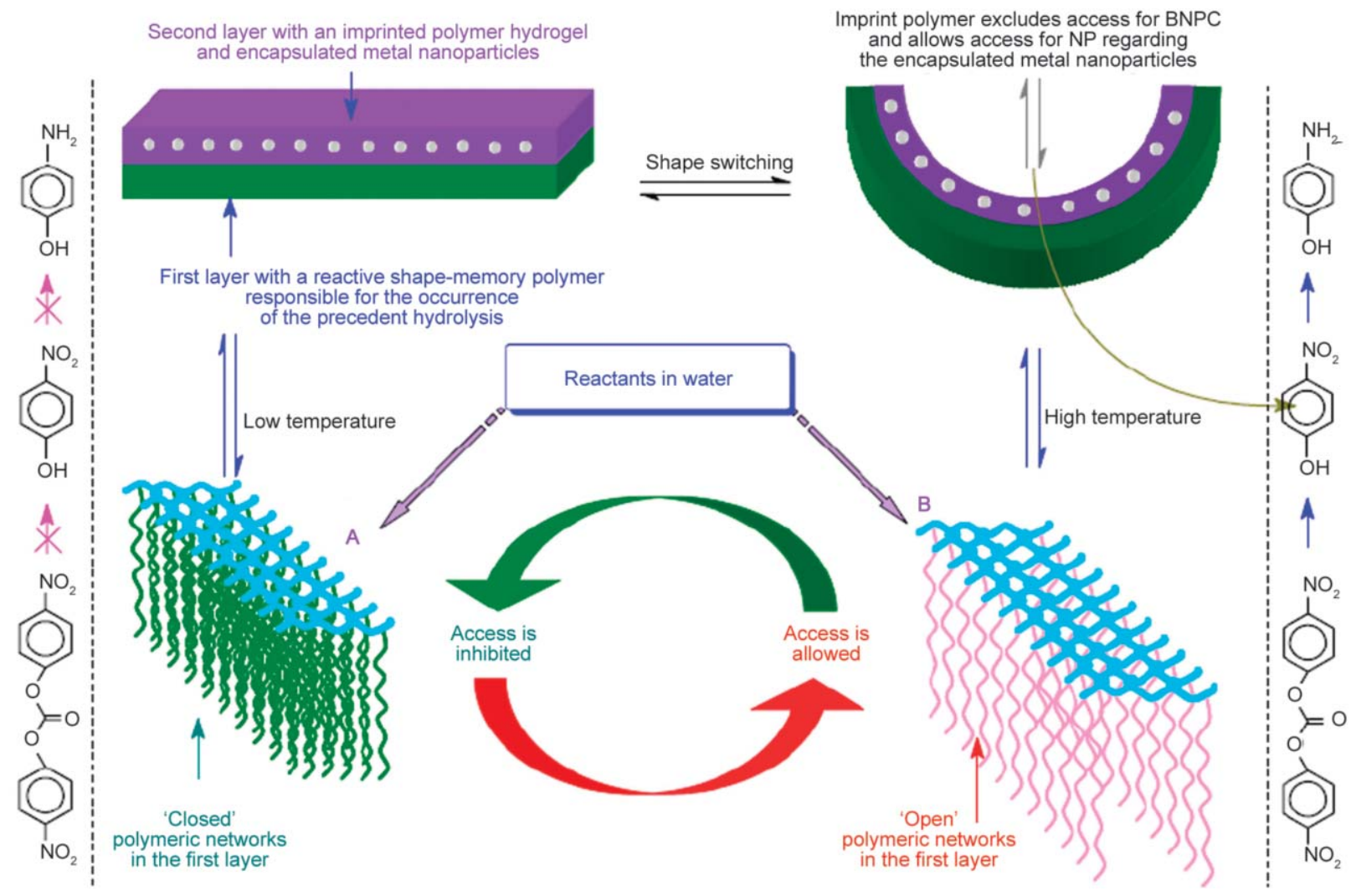

Figure 1. Technical outline for the proposed artificial reactor. 
the testing substrate and corresponding intermediate, since both compounds are a well-coupled pair for catalytic testing [18]. The catalytic hydrolysis of BNPC would lead to the formation of NP and meanwhile NP can be further reduced into 4-aminophenol (AP) in the presence of catalytic metal nanoparticles. The objective of this study is to demonstrate that tandem catalysts capable of self-controlled tandem catalytic-ability can be realized by developing artificial reactors, which accordingly suggests opportunities to develop controllable tandem processes.

\section{Experimental section}

\subsection{Preparation of reactors}

All the chemicals used are of analytic grade and were commercially available from Sigma-Aldrich (Saint Louis, USA). The artificial reactor, as mentioned above, was prepared in a bilayer form made of a shape-memory layer and a molecularly-imprinted layer (Figure 2). To connect the two layers [19], the shape-memory layer was first prepared with polymerization and then exposed by one side to the molecular-imprinting solution intended for preparing
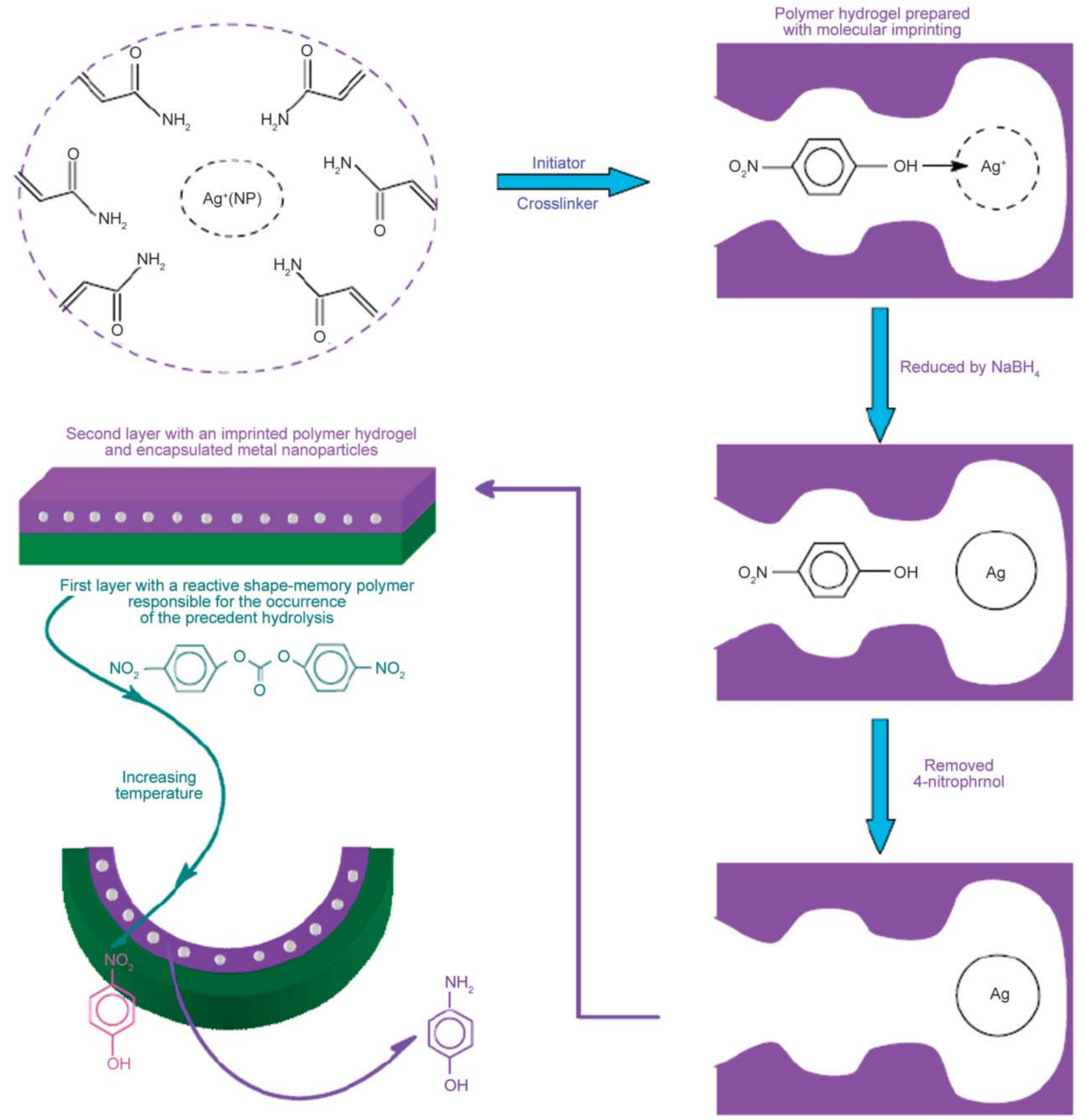

Figure 2. Schematic presentation of the preparation of the artificial bilayer reactor. 
the second layer (which allowed polymerizable monomers in the solution to diffuse into the shapememory layer). The molecular-imprinting solution was then polymerized with the addition of a radical initiator to form polymeric networks interpenetrated with the shape-memory layer. In this way, the both layers were connected. In detail, 2-nonenoic acid $(0.31 \mathrm{~g}), 2$-acrylamido-2-methylpropane-sulfonic acid $(2.90 \mathrm{~g}), N, N^{\prime}$-methylenebisacrylamide $(0.25 \mathrm{~g})$ and azobisisobutyronitrile $(0.10 \mathrm{~g})$ were dissolved in dimethyl-sulfoxide $(10 \mathrm{ml})$. After being dispersed and deoxygenated with sonication and blowing nitrogen, the mixture system was kept overnight for polymerization to form the shape-memory layer. Following this, one side of the shape-memory layer was exposed to the molecular-imprinting solution in which acrylamide $(1.42 \mathrm{~g})$, the complex template $\mathrm{Ag}^{+}(\mathrm{NP})(2.0 \mathrm{mmol}), N, N^{\prime}$-methylenebisacryl-amide $(0.24 \mathrm{~g})$ and azobisisobutyronitrile $(0.065 \mathrm{~g})$ were dissolved in dimethylsulfoxide $(5 \mathrm{ml})$. Polymerization was performed at $65^{\circ} \mathrm{C}$ for $3 \mathrm{~h}$ to prepare the imprinted hydrogel layer. The encapsulated silver ions were subsequently reduced with an excess of sodium borohydride. The imprinted NP was then removed from the reactor through refluxing in ethanol (containing 10 vol\% acetic acid). In this way, the artificial reactor was prepared (named 'SMP-MIPAg') (herein, 'SMP' means that the first layer was made of a shape-memory polymer. 'MIP' indicates that the second layer was made of a molecularly-imprinted polymer hydrogel, and 'Ag' means Ag nanoparticles).

Considering the artificial reactor which admitted switchable properties in the first layer and meanwhile allowed access to the succeeding reduction in the second layer, three control groups, named 'SMPNIP-Ag', 'NMP-A-MIP-Ag' and 'NMP-S-MIP-Ag', respectively, were also prepared under comparable conditions. In reference to the artificial reactor (i.e., SMP-MIP-Ag), SMP-NIP-Ag also admitted switchable properties in the first layer but denied further access in the second layer (i.e., adopting the corresponding non-imprinted hydrogel ('NIP') in the second layer). NMP-A-MIP-Ag and NMP-S-MIP-Ag were the non-switchable reactors that were prepared by replacing the switchable shape-memory layer with non-shape-memory layers ('NMP'). For the preparation of the two control groups, the thermosensitive component (i.e., 2-nonenoic acid) in the shape-memory layer of SMP-MIP-Ag was replaced with non-thermosensitive acrylic acid (marked by ' $A$ ' in NMP-A-MIP-Ag) and styrene (marked by ' $S$ ' in NMP-S-MIP-Ag), which did not contain thermosensitive networks $[16,17]$ and were therefore lack of the responsive properties. One more purpose for such replacement was to form a much stronger hydrophilic and hydrophobic environment in NMP-AMIP-Ag and NMP-S-MIP-Ag, which allowed either open or closed access to the first layers in the two control groups. In this way, these control groups, along with the artificial reactor, were prepared.

\subsection{Characterization}

The FTIR spectra of the prepared reactors were collected using a Nicolet MX-1E apparatus (Madison, USA). The TEM images were obtained using a JEOL JEM-2100 transmission electron microscope (TEM) (Akishima, Japan). The absorption bands of the surface plasma resonance (SPR) were recorded with a Shimadzu UV-2700 spectrophotometer (Tokyo, Japan). The energy-dispersive spectra (EDS) were obtained using a TESCAN MIRA3-XMU apparatus (Brno, Czech). The shape-memory effect was recorded with a digital camera in which the slices of the prepared reactors were immersed in water.

\subsection{Temperature-programmed desorption}

The temperature-programmed desorption (TPD) was used to address the interactions between the prepared imprinted-layers and the imprinted substrate [20,21]. For testing, the samples $(0.02 \mathrm{~g})$ scraped from the prepared imprinted-layers were placed into an online U-shaped quartz tube in a PCA-1200 TPD device (composed of a gas chromatography and a data processing system) (Beijing, China). After these samples pre-adsorbed with $1 \mu \mathrm{l}$ of substrate $\left(0.05 \mu \mathrm{mol} \cdot \mathrm{ml}^{-1}\right.$ acetonitrile), the quartz tube was heated in flowing nitrogen (velocity, $40 \mathrm{ml} \cdot \mathrm{min}^{-1}$; pressure, $0.25 \mathrm{MPa}$ ) at $10^{\circ} \mathrm{C} \cdot \mathrm{min}^{-1}$ from room temperature up to the temperature at which the absorbed substrate desorbed. The desorbing signal was recorded with the data processing system.

\subsection{Thermal transition behavior}

The thermal transition behavior in the prepared reactors was studied as a function of temperature by using dynamic light scattering (DLS) (Malvern Zetasizer, UK). For equilibrium, the samples $(0.01 \mathrm{~g})$ scraped from the shape-memory layers were kept at specified temperatures in water $(10 \mathrm{ml})$ for at least 
5 min before scanning the dynamic radius $\left(R_{\mathrm{d}}\right)$ [22]. By a comparison between the shape-memory layers and other non-responsive layers, the change of the dynamic radius reflected the contribution of the thermal transition.

\subsection{Catalytic properties}

The catalytic properties of the prepared reactors were evaluated with batch formats [23]. The initial concentration of BNPC was $0.2 \mu \mathrm{mol} \cdot \mathrm{ml}^{-1}(10 \mathrm{ml}$ PBS, pH 7.0) $\left(\mathrm{NaBH}_{4}\right.$-if present, fourfold in contrast to the concentration of BNPC). The content of the reactors used in every testing was $1.0 \cdot 10^{-3} \mathrm{~g} \cdot \mathrm{ml}^{-1}$. The catalytic behavior was spectrophotometrically monitored using a Shimadzu UV-2700 spectrophotometer (Tokyo, Japan) and the catalytic activities were determined from the average of triple runs. Considering the potential effect of spontaneous reactions on the catalytic process, the reactions of BNPC without having any reactors were also performed under the comparable conditions and accordingly the effect was deducted from the reported overall activities of these reactors.

\subsection{Desorption electrochemistry}

Desorption electrochemistry was further performed to acquire information on the controlled mechanisms in the prepared reactors [24, 25]. Using a CHI600E workstation equipped with a conventional threeelectrode configuration (i.e., Au-plate working electrode, Pt-wire counter electrode, and $\mathrm{Ag} / \mathrm{AgCl}$ reference electrode) (Shanghai, China), the prepared reactors $(0.01 \mathrm{~g})$ which pre-adsorbed with $\sim 2 \mathrm{mmol}$ of substrate were placed in an online electrochemical

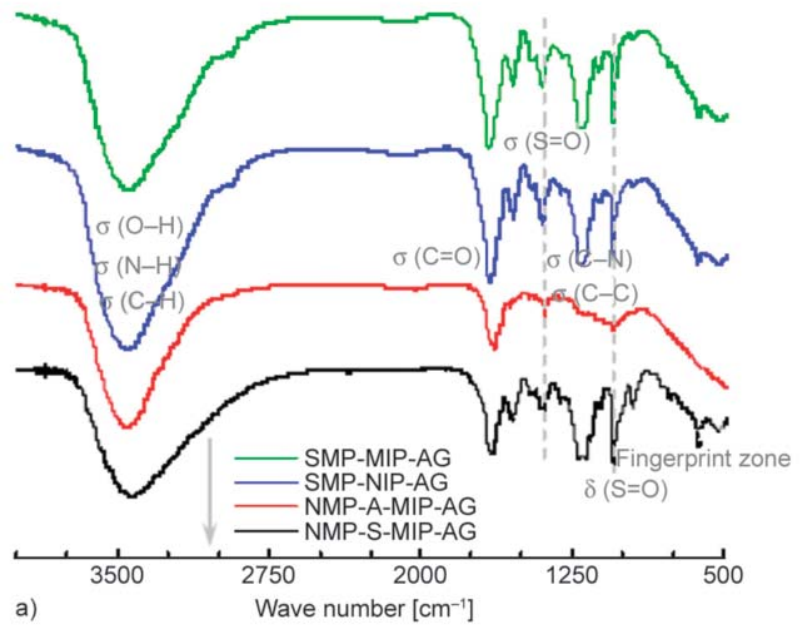

cell encircled by a diffusion-eliminating sonication apparatus (supporting electrolyte: $10 \mathrm{ml}$ PBS, $\mathrm{pH}$ 7.0). The desorbing behavior of the absorbed substrate was monitored by circularly scanning the system until a stable desorption profile was reached (scanning range, $+600 \sim 600 \mathrm{mV}$; scanning rate, $1 \mathrm{mV} \cdot \mathrm{s}^{-1}$ ).

\section{Results and discussion}

\subsection{FTIR, TEM, EDS and SPR analyses}

The artificial reactor, as explained, was prepared with polymeric bilayer architectures made of a shapememory layer and an imprinted layer. With the shapememory layer composite of PAMD, the imprinted layer was made of PAA and encapsulated metal nanoparticles. FTIR spectra are first used to track the polymeric composition in the both layers. As shown in Figure 3, three major bands (2950-3700, 1600-1810 and $1000-1350 \mathrm{~cm}^{-1}$ ) and some fingerprint bands (500-1000 $\mathrm{cm}^{-1}$ ) appeared in the spectra of the two layers, plus a few extra bands ( $\sim 1560$ and $\left.1050 \mathrm{~cm}^{-1}\right)$ in the shape-memory layer. These major bands were composite due to the multi-component composition in the reactor, spectroscopically corresponding to the stretching vibration of $\mathrm{O}-\mathrm{H}(\mathrm{N}-\mathrm{H}), \mathrm{C}=\mathrm{O}$ and $\mathrm{C}-\mathrm{N}$ $(\mathrm{C}-\mathrm{C})$ bonds and their rotation/bending in the two layers [26, 27], plus extra $\mathrm{S}=\mathrm{O}$ bands [28] in the shape-memory layer. These absorption bands involved in the two layers may be ascribed to the constituent monomers (i.e., 2-acrylamido-2-methylpropane-sulfonic acid and 2-nonenoic acid in the first layer and acrylamide in the second layer) which all included $\mathrm{O}-\mathrm{H}(\mathrm{N}-\mathrm{H}), \mathrm{C}=\mathrm{O}$, and $\mathrm{C}-\mathrm{N}(\mathrm{C}-\mathrm{C})$ bonds. The extra exhibition of $\mathrm{S}=\mathrm{O}$ bands, along with these major bands, in the shape-memory layer

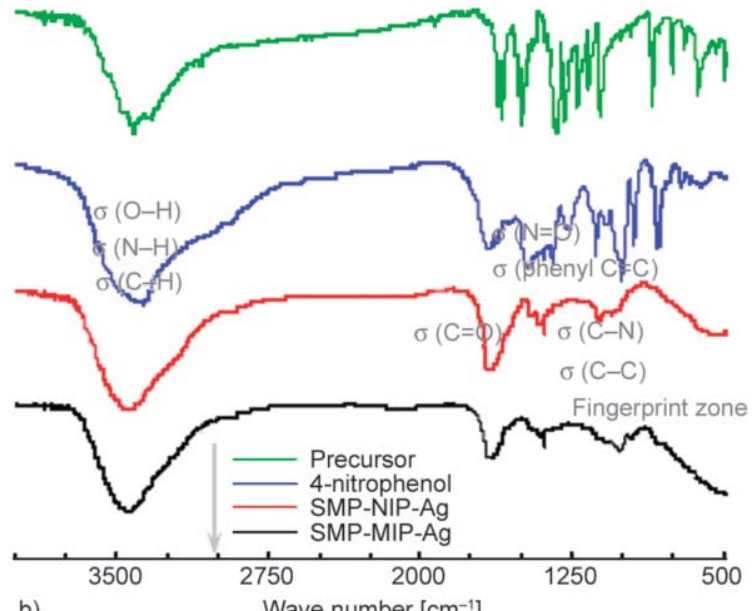

b)

Figure 3. FTIR spectra of polymeric bilayers in the prepared reactors. a) Shape-memory layer; b) imprinted layer. 
revealed the polymeric composition composite of PAMD. For further addressing this, we also include the FTIR spectra of these control groups described above in Figure 3. All the control groups showed almost the same spectra as the artificial reactor and included $\mathrm{S}=\mathrm{O}$ bands in the first layers. This outcome indicates that the artificial reactor SMP-MIP-Ag was the polymeric reactor composite of PAMD in the first layer.

For tracking the imprinting behavior in the second layer, we include the FTIR spectra of both the SMPMIP-Ag precursor (in which the imprinted NP has not been removed from the polymeric matrix) and NP, along with SMP-MIP-Ag and the non-imprinted SMP-NIP-Ag, in Figure 3b. The SMP-MIP-Ag precursor exhibited the major absorption bands of both SMP-MIP-Ag and NP in the spectrum. After
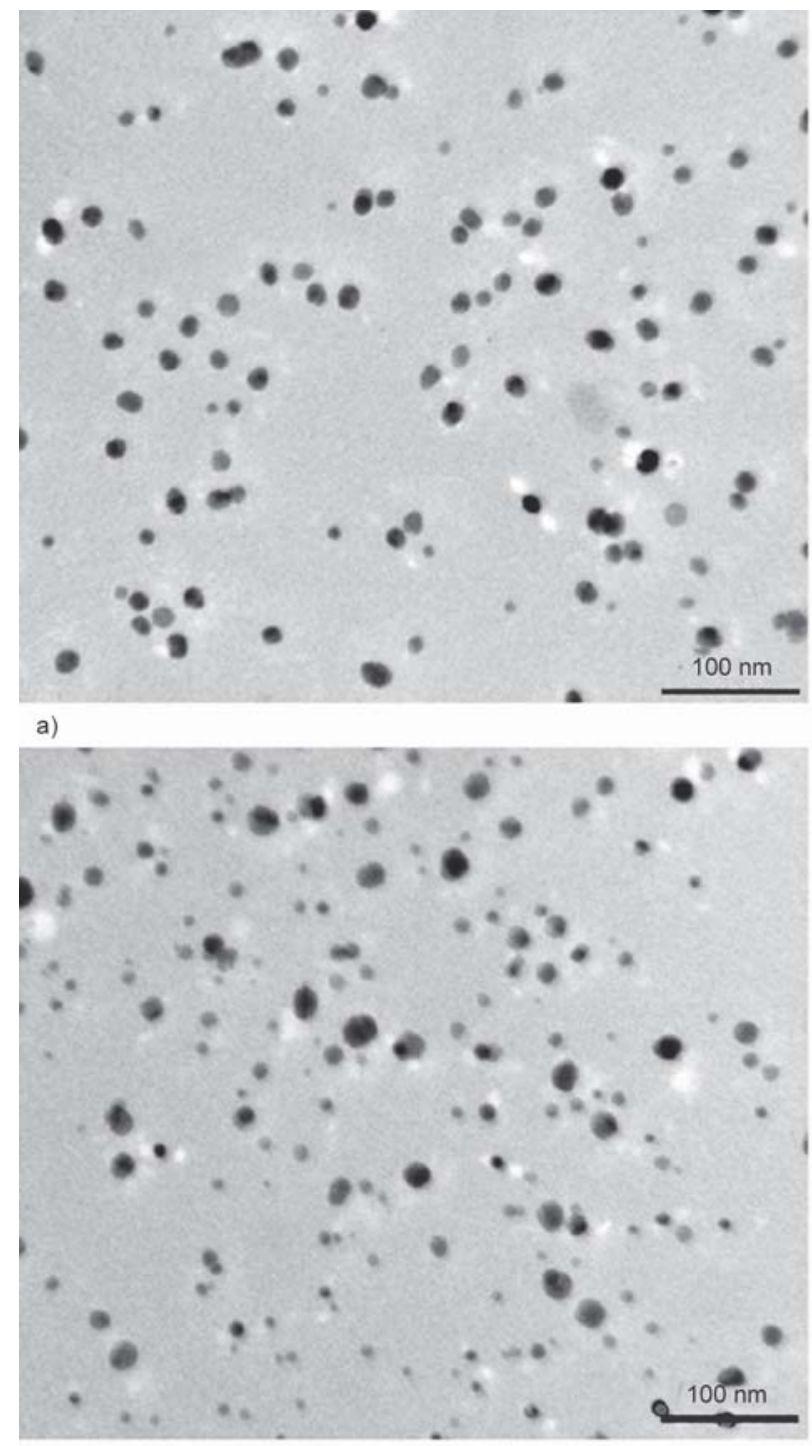

c) removing the imprinted NP from the precursor, the spectrum of the resulting reactor (i.e., SMP-MIP-Ag) became comparable to that of SMP-NIP-Ag. In association with the preparation process (cf. Figure 2), this outcome indicates the occurrence of the imprinting behaviors (the further discussion on the imprinted interactions is shown in Section 3.2). Figure 4 presents the TEM images, displaying the metal nanoparticles encapsulated in these prepared reactors. Ag nanoparticles with a size of $\sim 20 \mathrm{~nm}$ were encapsulated in these prepared reactors (the minor uneven distribution in particle sizes may be due to a restriction from reducers diffusing during the reduction process [29]). The presence of Ag nanoparticles was further evidenced by the EDS and SPR spectra (typically at $\sim 420 \mathrm{~nm}$ ) [30] and accordingly the Ag loadings (acting as the catalytic reduction sites) and $\mathrm{S}$ contents
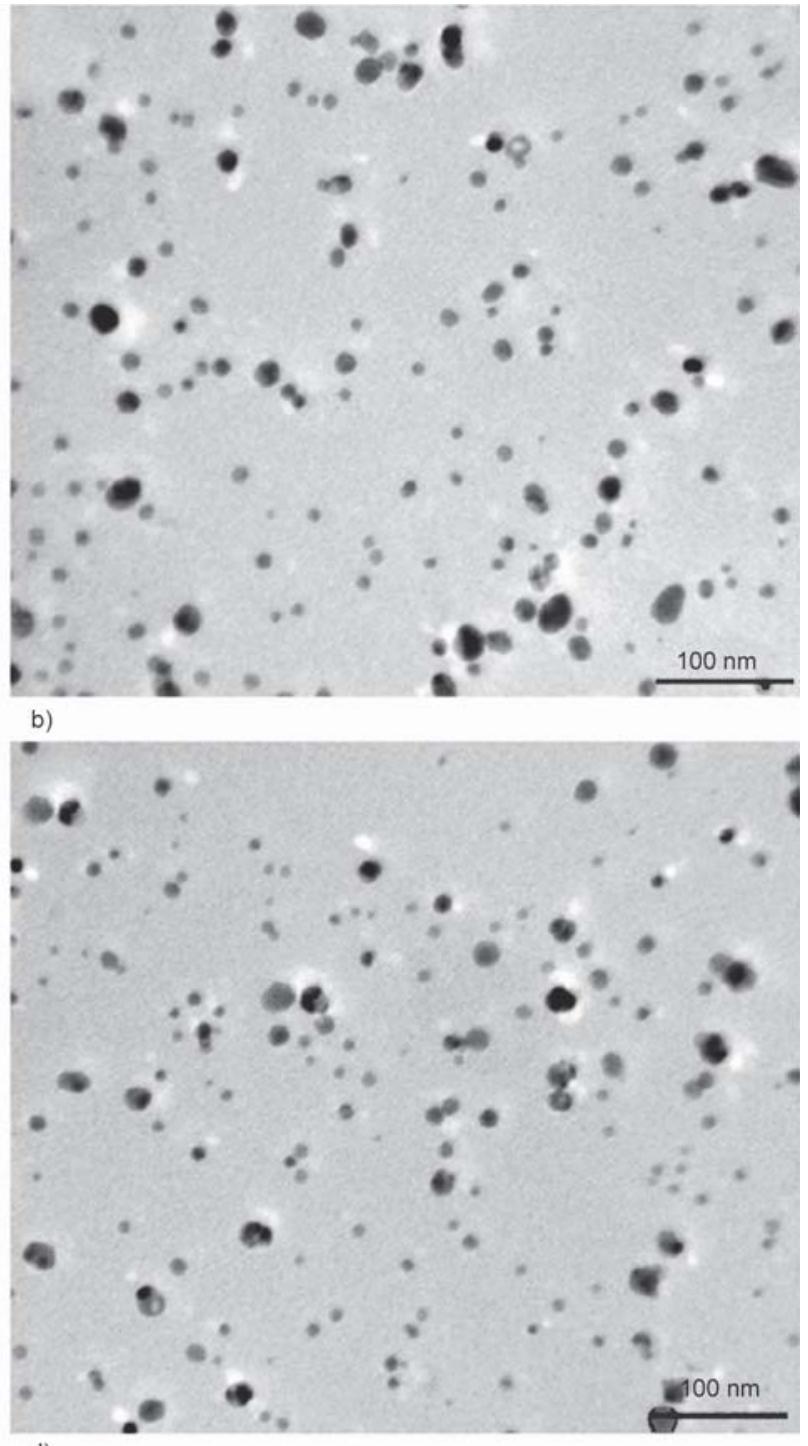

Figure 4. TEM images of metal nanoparticles encapsulated in the prepared reactors. a) SMP-MIP-Ag; b) SMP-NIP-Ag; c) NMP-A-MIP-Ag; d) NMP-S-MIP-Ag. 


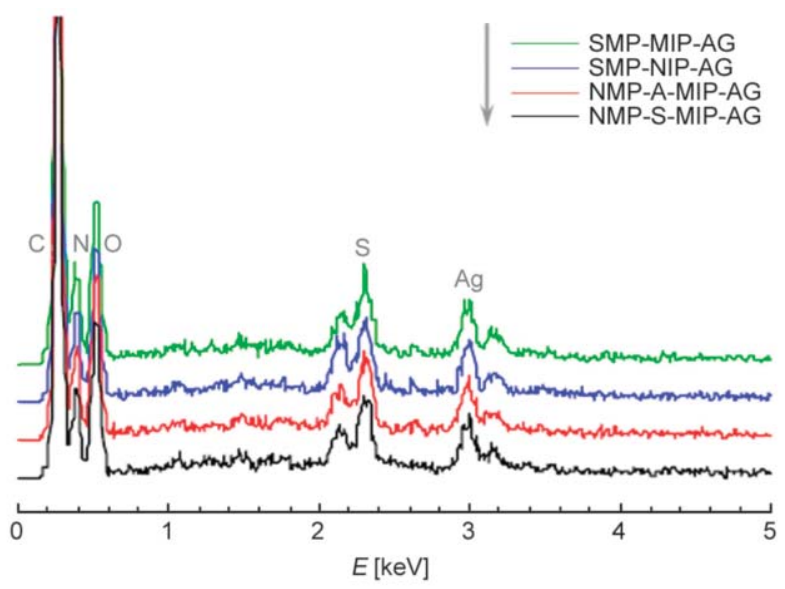

Figure 5. EDS of the prepared reactors.

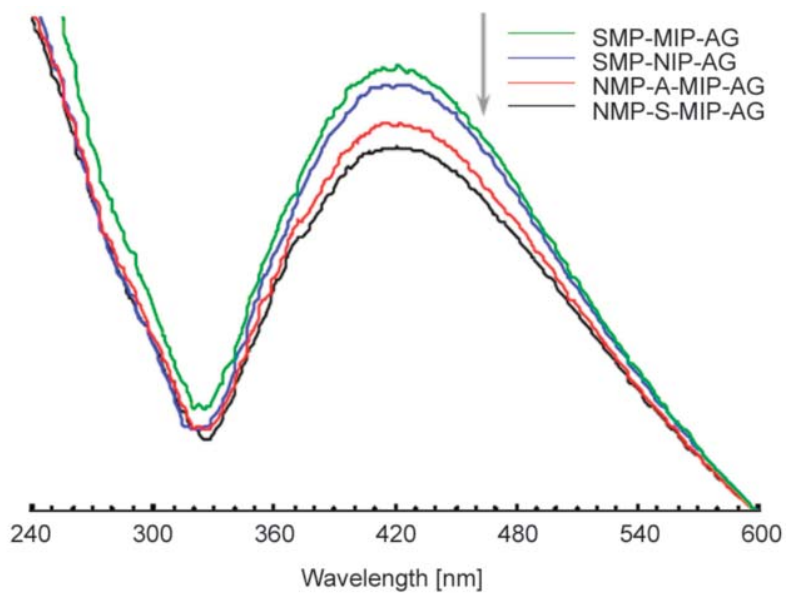

Figure 6. SPR spectra of the prepared reactors.

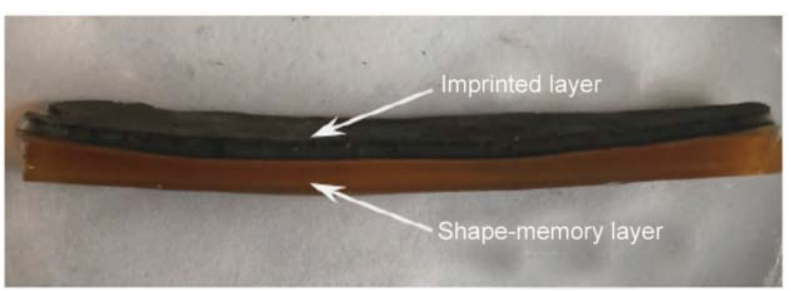

Figure 7. Digital image of a slice of SMP-MIP-Ag.

$\left(-\mathrm{SO}_{3} \mathrm{H}\right.$ acting as acidic sites) contained in these reactors were $\sim 3.92$ and $8.15 \mathrm{wt} \%$, respectively (Figures 5 and 6). Figure 7 displays the digital picture of SMP-MIP-Ag. The artificial reactor demonstrated the expected bilayer structure. Hence, these reactors were prepared in the desired form.

\subsection{Temperature-programmed desorption}

The TPD was further performed to address the interactions between the imprinted layers and the imprinted substrate in these prepared reactors. Relatively, a stronger interaction in the imprinted layers would allow the reactors to have larger retention, in contrast to a weaker interaction. As shown in Figure 8 , the imprinted substrate NP which desorbed from SMP-MIP-Ag, SMP-NIP-Ag, NMP-A-MIP-Ag and NMP-S-MIP-Ag appeared at 267, 223, 270 and $263^{\circ} \mathrm{C}$, respectively. The imprinted reactors (i.e., SMP-MIP-Ag, NMP-A-MIP-Ag and NMP-S-MIP$\mathrm{Ag}$ ) showed stronger interactions with NP, in contrast to the non-imprinted SMP-NIP-Ag. The imprinted species played a role in leading to stronger interactions in these prepared reactors. For further addressing this, we also include the contrastive TPD profiles in which NP desorbing from these reactors was replaced with BNPC desorbing from these reactors in Figure 8 (cf. Figure 8b). There were no essential differences in the desorption behavior of BNPC among these reactors. In association with the track of the imprinting behaviors in Section 3.1, this outcome reflects again the consequence of molecular imprinting. Since the interactions derived from the imprinted species are essentially a result of the induced molecular memory (i.e., the 'copy' of the imprinted substrate), the stronger interactions in the imprinted reactors were to be expected. In this way, these prepared reactors, due to the imprinted species, led to larger retention in the TPD profiles.

\subsection{Shape-memory effect and thermosensitive transition}

Figure 9 displays the shape change of the artificial reactor upon changing temperature. The slice of the reactor appeared flat at $20^{\circ} \mathrm{C}$ but convex at or above $40^{\circ} \mathrm{C}$. The change in shapes was reversible and this reactor can be made to switch back and forth between the flat and convex shapes. The artificial reactor showed the desired shape-memory effect. This outcome, as known, may be related to the thermosensitive polymeric networks in the shape-memory layer [16]. The switching between the open- and closed networks induced the shape change in this reactor.

For further addressing the thermosensitive networks, the dynamic radius $\left(R_{\mathrm{d}}\right)$ of the shape- memory layer was studied as a function of temperature. As shown in Figure 10, the dynamic radius of the shape-memory layer showed essential dependence on temperature, in contrast to other non-responsive layers which did not contain thermosensitive networks. The dynamic radius of the shape-memory layer increased with increasing temperature and the major change appeared at $\sim 38^{\circ} \mathrm{C}$ (marked by a small circle). Below the temperature, the shape-memory layer showed relatively a smaller dynamic radius associating with the closed polymeric networks [17]. Above the transition 

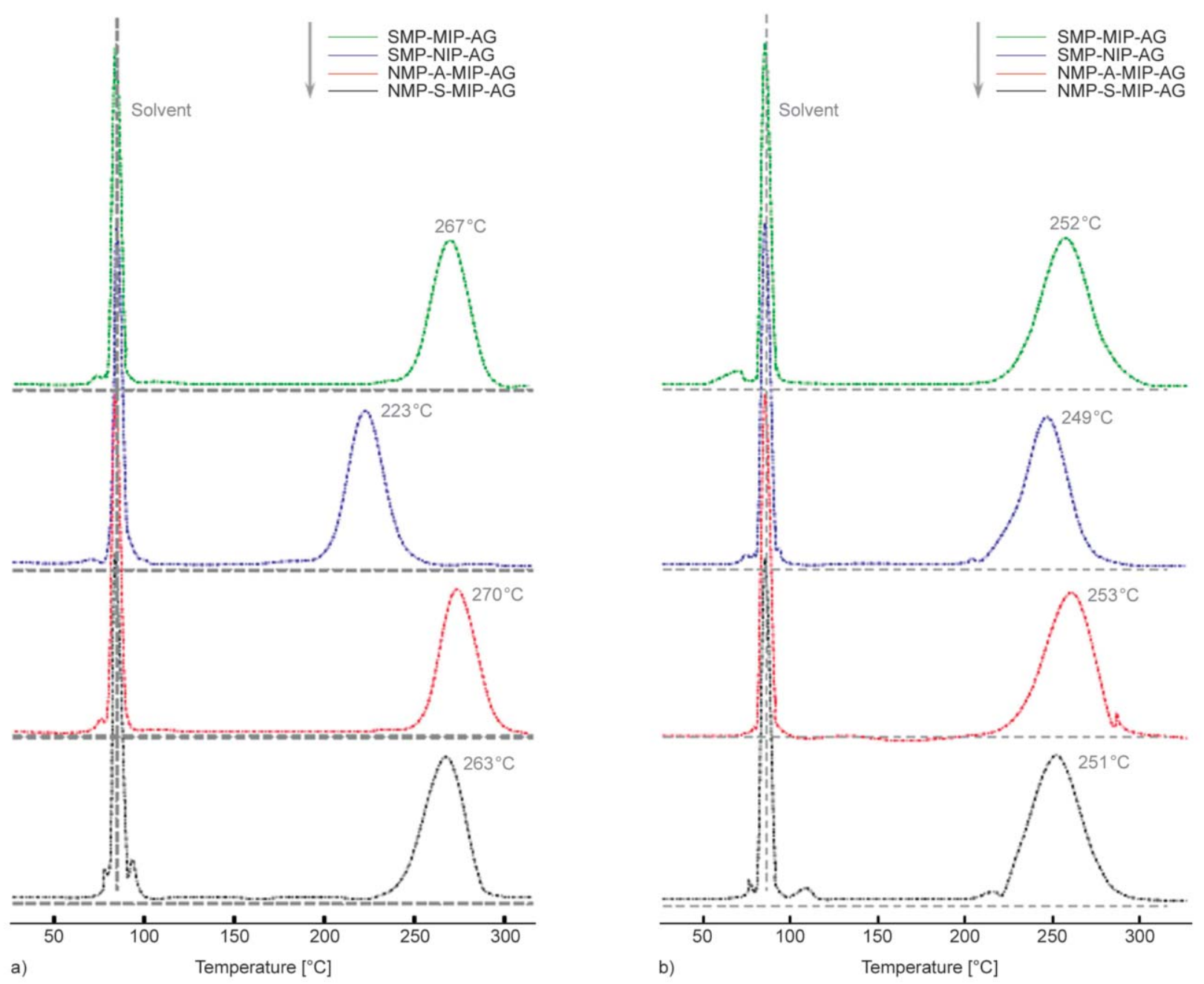

Figure 8. TPD profiles of the prepared reactors for NP (a) and BNPC (b) desorbing.

temperature, the dynamic radius of the shape-memory layer dramatically increased in response to the activation of these networks. The switching process was repeatable due to the reversibility of the chain motion in these networks. These outcomes therefore reveal that the alterable shape at the artificial reactor was a result of the thermosensitive networks in this reactor.

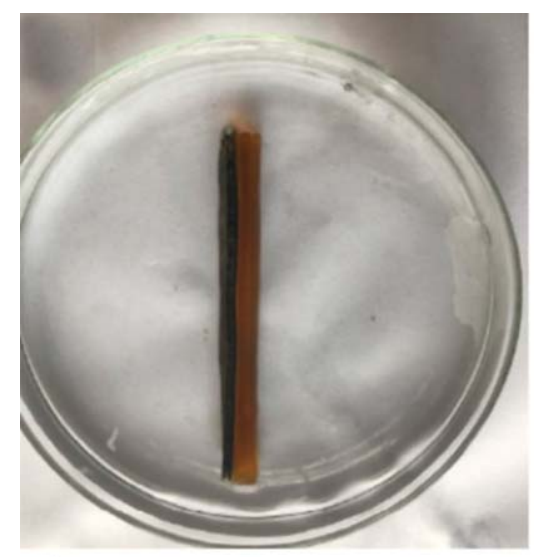

a)

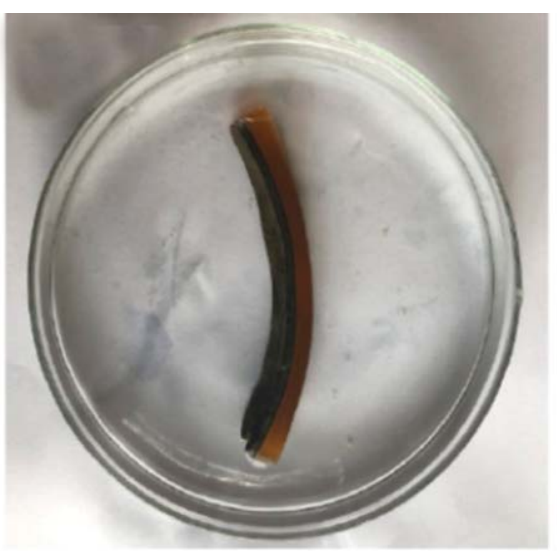

b)

\subsection{Tandem catalysis occurred with self-controlled molecular switch}

Considering the entire tandem process of BNPC which was made of two consecutive steps, the catalytic activities were therefore first tested in the absence of sodium borohydride (a reducer for the succeeding reaction), which allowed one to catch a

Figure 9. Shape changing in the artificial reactor upon temperature, a) $20^{\circ} \mathrm{C}$; b) $40^{\circ} \mathrm{C}$; c) $55^{\circ} \mathrm{C}$. 

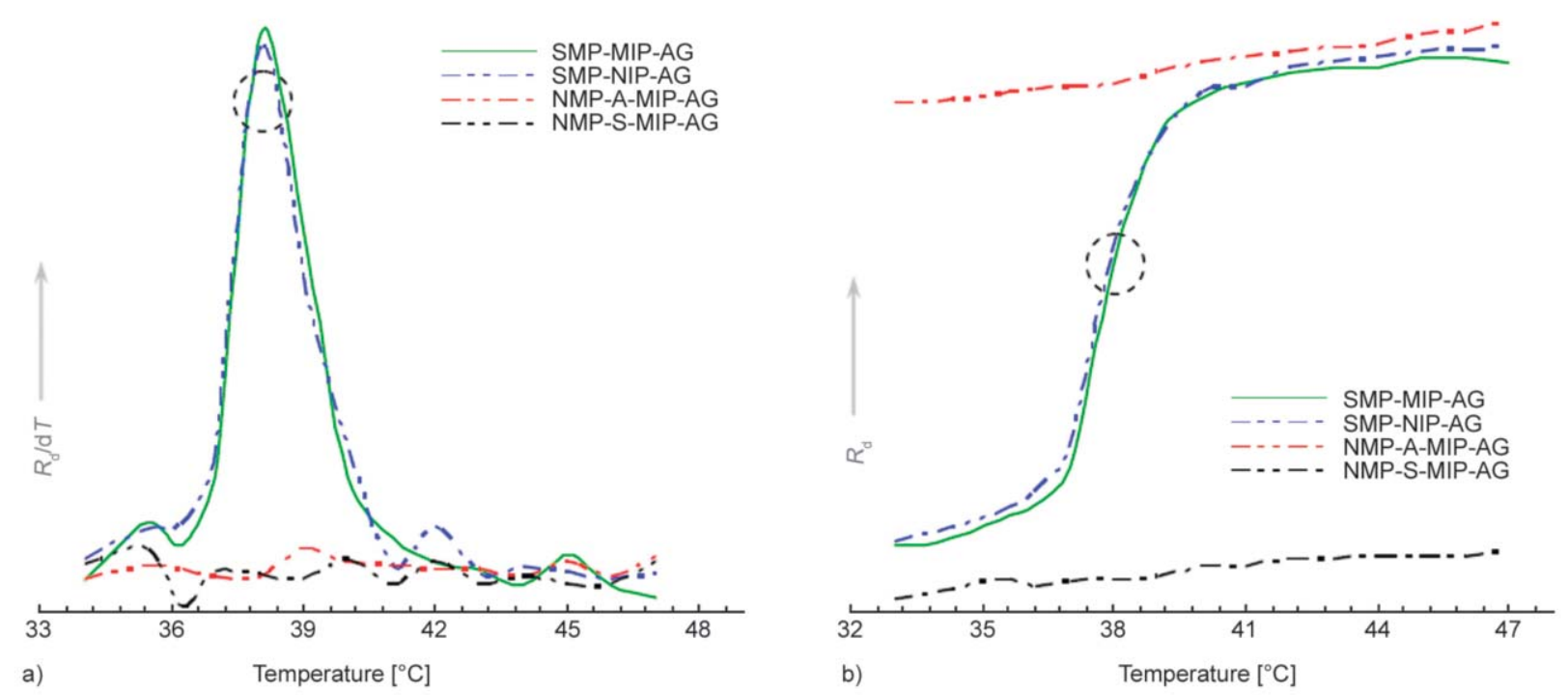

Figure 10. DLS spectra with the dynamic radius changing as a function of temperature. a) Differential; b) normal.

glimpse into the self-controlled behavior in one individual step (such as the catalytic hydrolysis). By taking the switchable properties in the first layer into account, two representative temperatures, i.e., 20 and $55^{\circ} \mathrm{C}$, which are either higher or lower than the transition temperature at the artificial reactor (i.e., $\sim 38^{\circ} \mathrm{C}$; cf. Figure 10 ), were selected for the catalytic testing. The purpose of selecting such temperatures was to ensure that the switchable zones can be covered (cf. Figure 1). As shown in Figure 11, at $55^{\circ} \mathrm{C}$, SMP-MIP-Ag behaved like NMP-A-MIP-Ag (which ran with open networks) and showed significant activities for the catalytic hydrolysis of BNPC (marked by a solid-line circle). In contrast, at $20^{\circ} \mathrm{C}$, SMPMIP-Ag behaved like NMP-S-MIP-Ag (which ran with closed networks) and did not show essential activities (marked by a dotted-line circle). The artificial reactor SMP-MIP-Ag demonstrated the desired

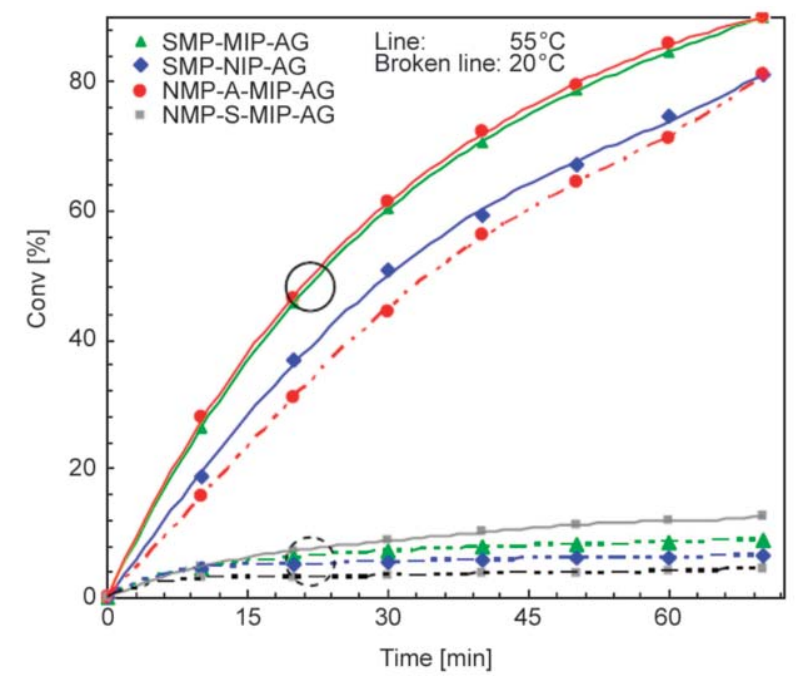

Figure 11. Hydrolytic activities of BNPC at the prepared reactors. switchable catalytic ability. In combination with the coupled imprinted layer, one can expect the occurrence of self-controlled tandem catalytic-ability at this artificial reactor, in which the switchable properties in the shape-memory layer may act as a molecular switch for the precedent process whereas the coupled imprinted-layer would provide access to the succeeding process. In this way, this artificial reactor led to the occurrence of self-controlled tandem catalytic ability.

For tracking this, UV spectroscopic analysis was first performed to monitor the catalytic process in the presence of sodium borohydride at $55^{\circ} \mathrm{C}$, which allowed the shape-memory layer of the artificial reactor to run with open networks. As shown in Figure 12a, the catalytic process of BNPC at SMP-NIPAg led to a decreasing peak for BNPC $(272 \mathrm{~nm})$ and meantime an increasing peak for NP (400 nm), exhibiting the catalytic hydrolysis from BNPC into NP. There was no tandem catalytic process available at SMP-NIP-Ag due to the lack of access to the encapsulated Ag nanoparticles in the non-imprinted layer. In contrast, the catalytic process of BNPC at the artificial reactor SMP-MIP-Ag was remarkably different from that of SMP-NIP-Ag, in which the catalysis led to a decreasing peak for BNPC $(272 \mathrm{~nm})$ and nonetheless an increasing peak for AP $(295 \mathrm{~nm})$ (Figure 12b). The forming intermediate NP was further reduced into AP. As desired, the tandem catalytic process occurred at SMP-MIP-Ag.

For further addressing this, UV spectroscopic analysis was performed again at $20^{\circ} \mathrm{C}$ to monitor the catalytic process, which allowed the shape-memory layer of the artificial reactor to run with closed networks. 

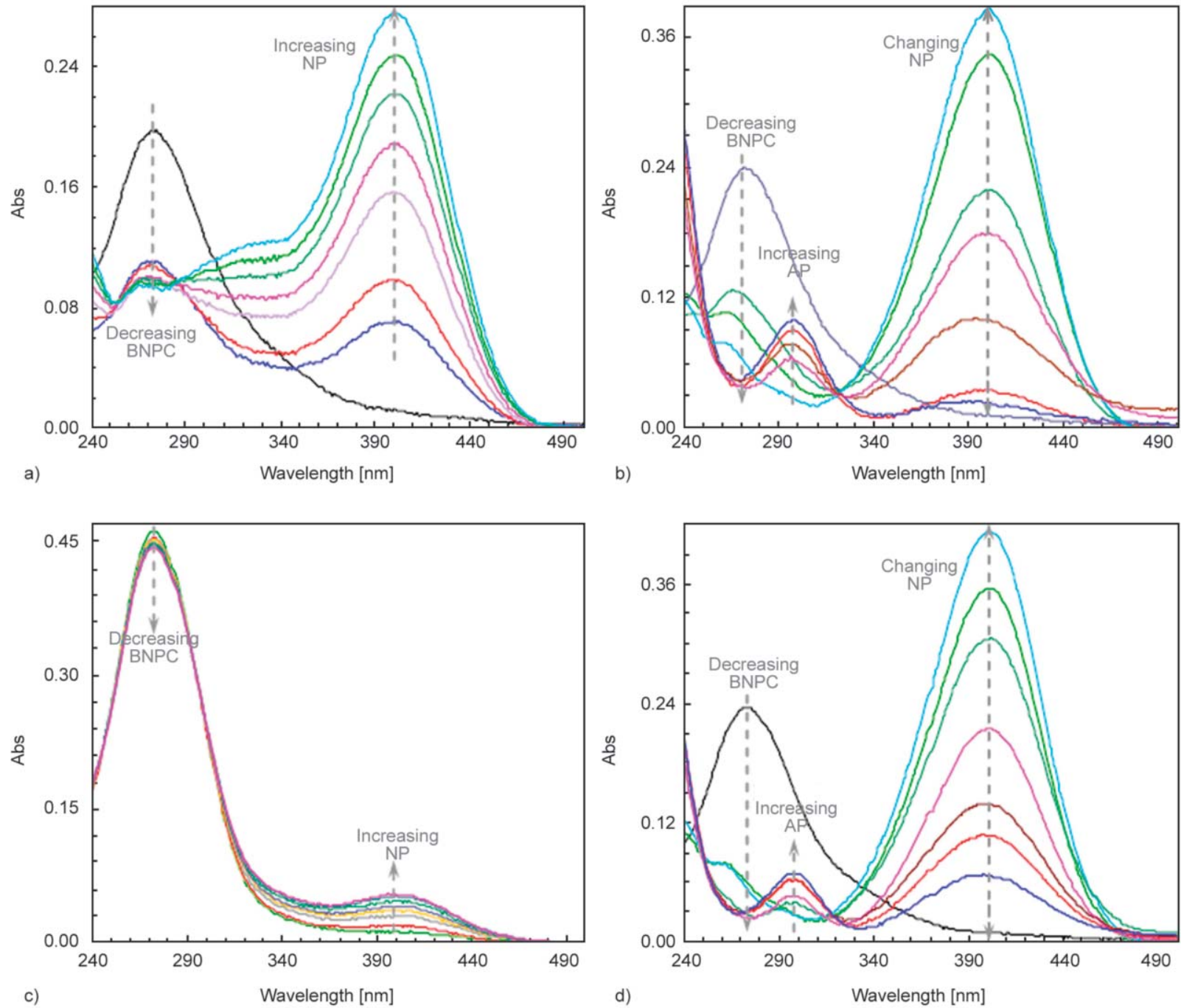

Figure 12. The changing UV spectrum of BNPC in the presence of sodium borohydride at the prepared reactors. a) SMPNIP-Ag at $55^{\circ} \mathrm{C}$; b) SMP-MIP-Ag at $55^{\circ} \mathrm{C}$; c) SMP-MIP-Ag/SMP-NIP-Ag/NMP-S-MIP-Ag at $20^{\circ} \mathrm{C}$; d) NMPA-MIP-Ag at $20^{\circ} \mathrm{C}$.

There was no essential tandem catalysis available at all the prepared reactors (Figure 12c) except NMPA-MIP-Ag which exhibited tandem catalytic ability due to the open access in the first layer (Figure 12d). This outcome indicates that the desired self-controlled tandem catalytic ability occurred at SMPMIP-Ag.

\subsection{Dynamic binding and controlled access}

Desorption electrochemistry was further performed to acquire information on the controlled mechanisms in the prepared reactors. As far as polymeric reactors and their controlled mechanisms are concerned, the fundamental issues are known to lie in the interactions between these reactors and substrate [31]. Hence, addressing the interactions between these reactors and substrate is a key for unfolding the controlled mechanisms. For the point, it has been known that the potential to reduce/oxidize a binding molecule is dependent upon the binding strength. Relatively, stronger binding would need more energy to overcome the binding, accordingly resulting in a larger redox potential. The detailed theory, as outlined in Figure 13, has been described elsewhere [24, 25]. Despite the reactions, the binding substrate in the electrochemical system would normally involve desorption, diffusion to the surface of the electrodes, and a terminal redox process. Once the diffusion is eradicated with sonication, the desorbing behavior of the binding substrate is therefore directly related to the change of the redox potential. Considering the

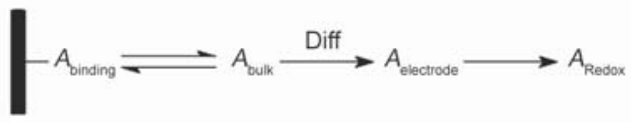

Figure 13. Schematic presentation of the electrochemical desorption with a binding molecule $A$. 

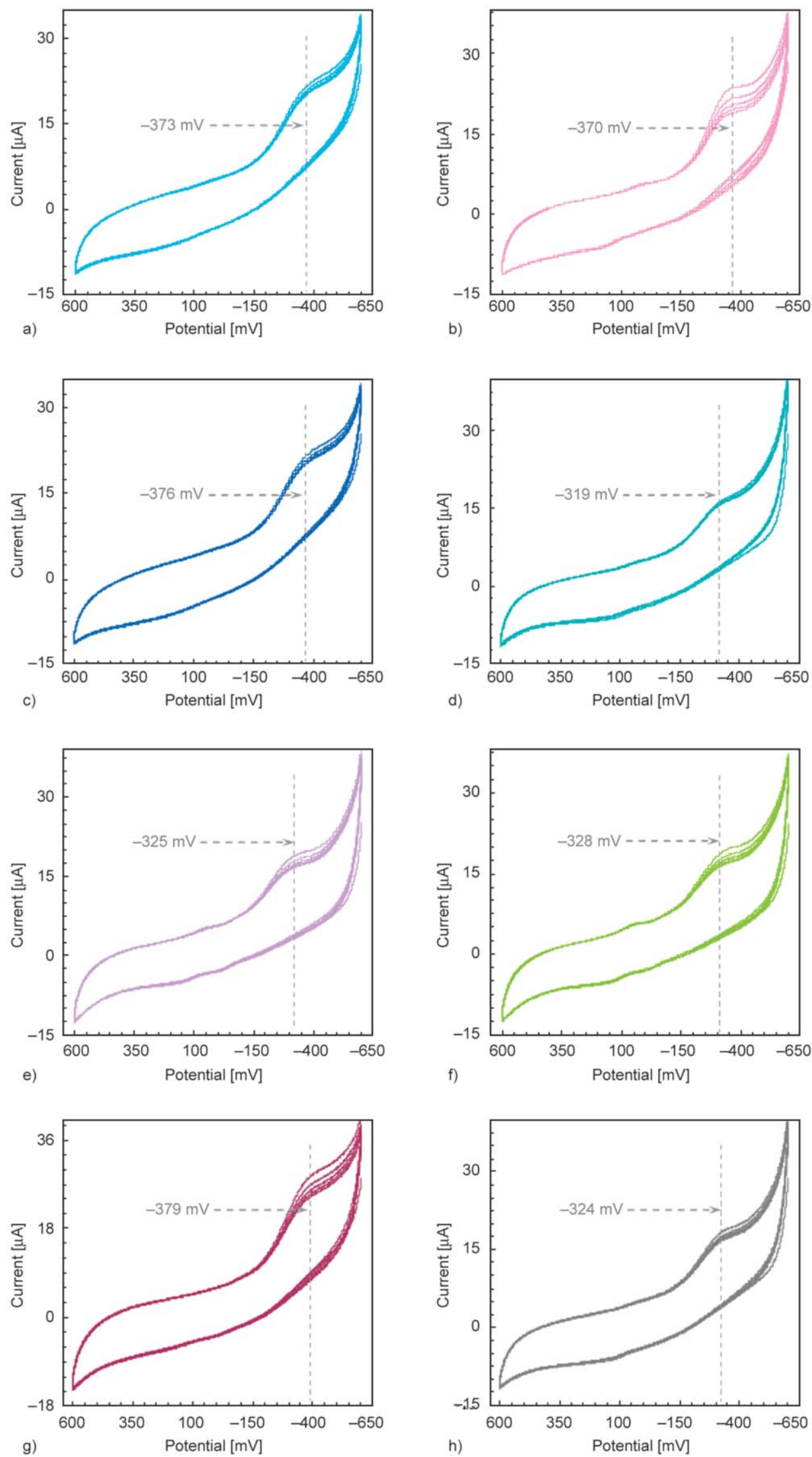

Figure 14. Desorption-reduction potentials with substrate desorbing from all the prepared reactors. a) SMP-MIP-Ag at $55^{\circ} \mathrm{C}$; b) SMP-NIP-Ag at $55^{\circ} \mathrm{C}$; c) NMP-A-MIP-Ag at $55^{\circ} \mathrm{C}$; d) NMP-S-MIP-Ag at $55^{\circ} \mathrm{C}$; e) SMP-MIP-Ag at $20^{\circ} \mathrm{C}$; f) SMP-NIP-Ag $20^{\circ} \mathrm{C}$; g) NMP-A-MIP-Ag at $20^{\circ} \mathrm{C}$; h) NMP-S-MIP-Ag at $20^{\circ} \mathrm{C}$. 
switchable properties in the first layer of the artificial reactor, 55 and $20^{\circ} \mathrm{C}$ were selected again for a comparative study. As shown in Figure 14 , at $55^{\circ} \mathrm{C}$, BNPC which was bound to the first layers of SMPMIP-Ag, SMP-NIP-Ag, NMP-A-MIP-Ag and NMP-S-MIP-Ag exhibited the desorption-reduction potentials at $-373,-370,-376$ and $-319 \mathrm{mV}$, respectively (Figure 14a-14d). These desorption-reduction potentials at $20^{\circ} \mathrm{C}$ shifted, however, into $-325,-328$, -379 and $-324 \mathrm{mV}$, respectively (Figure $14 \mathrm{e}-14 \mathrm{~h}$ ). At $55^{\circ} \mathrm{C}$, the artificial reactor SMP-MIP-Ag appeared like NMP-A-MIP-Ag (which ran with open access) ( -373 vs. $-376 \mathrm{mV})$ and showed a stronger interaction with BNPC, in contrast to NMP-S-MIP$\mathrm{Ag}$ which ran with closed access $(-319 \mathrm{mV})$. At $20^{\circ} \mathrm{C}$, the artificial reactor SMP-MIP-Ag behaved, however, like NMP-S-MIP-Ag (which ran with closed access) ( -325 vs. $-324 \mathrm{mV})$ and showed a weaker interaction with BNPC, in contrast to NMPA-MIP-Ag which ran with open access $(-379 \mathrm{mV})$. The switchable properties in the first layer of the artificial reactor acted as a molecular switch in controlling access.

For tracking this, Table 1 shows the desorption-reduction potentials for both BNPC and NP desorbing from all the involved layers in these prepared reactors. There were no essential differences in the interactions between NP and the imprinted layers. The imprinted layers played only a role in providing access to the encapsulated metal nanoparticles. In association with the switchable properties in the shapememory layer, these outcomes indicate that the self-controlled tandem catalytic-ability at the artificial reactor was a result of the cooperative work of the two functional layers. The shape-memory layer acted as a molecular switch for the occurrence of the

Table 1. Desorption-reduction potentials with substrate desorbing from all the prepared reactors.

\begin{tabular}{|c|c|c|c|c|}
\hline \multirow{2}{*}{$\begin{array}{l}\text { Layer and } \\
\text { its role }\end{array}$} & \multirow[t]{2}{*}{ Reactor } & \multicolumn{2}{|c|}{$\begin{array}{l}\text { Reduction potential } \\
\qquad[\mathrm{mV}]\end{array}$} & \multirow{2}{*}{$\begin{array}{l}\text { Delta } \\
{[\mathrm{mV}]}\end{array}$} \\
\hline & & $20^{\circ} \mathrm{C}$ & $55^{\circ} \mathrm{C}$ & \\
\hline \multirow{4}{*}{$\begin{array}{l}\text { First layer } \\
\text { for BNPC }\end{array}$} & SMP-MIP-Ag & -325 & -373 & -48 \\
\hline & SMP-NIP-Ag & -328 & -370 & -42 \\
\hline & NMP-A-MIP-Ag & -379 & -376 & 3 \\
\hline & NMP-S-MIP-Ag & -324 & -319 & 5 \\
\hline \multirow{4}{*}{$\begin{array}{l}\text { Coupled } \\
\text { second } \\
\text { layer for } \\
\text { NP }\end{array}$} & SMP-MIP-Ag & -245 & -241 & 4 \\
\hline & SMP-NIP-Ag & -248 & -243 & 5 \\
\hline & NMP-A-MIP-Ag & -250 & -246 & 4 \\
\hline & NMP-S-MIP-Ag & -246 & -243 & 3 \\
\hline
\end{tabular}

precedent reaction of BNPC whereas the coupled imprinted-layer provided access to the succeeding reduction. In this way, the artificial reactor led to the occurrence of the self-controlled tandem catalyticability.

\section{Conclusions}

In this study, we met the present challenges in tandem catalysts by reporting an artificial reactor which was capable of self-controlled tandem catalytic-ability. This artificial reactor was fabricated with polymeric bilayer architectures containing a reactive shape-memory layer and a coupled imprinted-layer. The reactive shape-memory layer consisted of poly (2-acrylamido-2-methyl-propanesulfonic acid-co-2nonenoic acid) (PAMD), whereas the coupled imprinted-layer was made of bis(4-nitrophenyl)carbonate-imprinted poly(acrylamide) (PAA) hydrogel and encapsulated Ag nanoparticles. The thermo $\neg$ sensitive properties of PAMD enabled the reactor to act as a molecular switch for the occurrence of the precedent hydrolysis of bis(4-nitrophenyl)carbonate. The coupled imprinted-layer provided access to the succeeding reduction of the intermediate 4-nitrophenol. In a cooperative way, the bilayer architectures led to the occurrence of the self-controlled tandem catalytic-ability at this artificial reactor. It is therefore confirmed that tandem catalysts capable of selfcontrolled tandem catalytic ability can be realized by developing artificial reactors. The strategy of developing the artificial reactor suggests a promising prospect to formulate controllable tandem catalytic processes. The sustainable endeavors in the future will help increase the potential for applications and lead to the appearance of novel functional catalytic materials.

\section{Acknowledgements}

The authors want to express their gratitude to the National Natural Science Foundation of China (Nos. 51473070 and 51808263). Thanks also should be expressed to the Government of Jiangsu Province for supporting this study under the innovation-entrepreneurship program (Surencaiban [2015]26).

\section{References}

[1] Xiao P., Wu S., Shen X., Zhu M., Li S.: Smart tandem catalyst developed with sundew's predation strategy, capable of catching, decomposing and assimilating preys. ChemCatChem, 10, 5231-5241 (2018).

https://doi.org/10.1002/cctc.201801537 
[2] Corma A., Navas J., Sabater M. J.: Advances in onepot synthesis through borrowing hydrogen catalysis. Chemical Reviews, 118, 1410-1459 (2018).

https://doi.org/10.1021/acs.chemrev.7b00340

[3] Che H., Cao S., van Hest J. C. M.: Feedback-induced temporal control of 'breathing' polymersomes to create self-adaptive nanoreactors. Journal of the American Chemical Society, 140, 5356-5359 (2018).

https://doi.org/10.1021/jacs.8b02387

[4] Liu H., Liu L., Guo W-D., Lu Y., Zhao X-L., Liu Y.: Phosphine-ligated Ir(III)-complex as a bi-functional catalyst for one-pot tandem hydroformylation-acetalization. Journal of Catalysis, 373, 215-221 (2019).

https://doi.org/10.1016/j.jcat.2019.04.004

[5] Han L., Zhang H., Chen D., Li F.: Protein-directed metal oxide nanoflakes with tandem enzyme-like characteristics: Colorimetric glucose sensing based on one-pot enzyme-free cascade catalysis. Advanced Functional Materials, 28, 1800018/1-1800018/9 (2018).

https://doi.org/10.1002/adfm.201800018

[6] Brändel T., Sabadasch V., Hannappel Y., Hellweg T.: Improved smart microgel carriers for catalytic silver nanoparticles. ACS Omega, 4, 636-4649 (2019). https://doi.org/10.1021/acsomega.8b03511

[7] Kureha T., Nagase Y., Suzuki D.: High reusability of catalytically active gold nanoparticles immobilized in core-shell hydrogel microspheres. ACS Omega, 3, 6158-6165 (2018).

https://doi.org/10.1021/acsomega.8b00819

[8] Xia H., Zhang Z., Liu J., Ning X., Zhang S., Lu X.: Developing superior catalysts engineered by multichannel healing strategy for advanced oxidation. Applied Catalysis B: Environmental, 250, 189-199 (2019). https://doi.org/10.1016/j.apcatb.2019.03.033

[9] Choudhury J.: Recent developments on artificial switchable catalysis. Tetrahedron Letters, 59, 487-495 (2018). https://doi.org/10.1016/j.tetlet.2017.12.070

[10] Eisenreich F., Kathan M., Dallmann A., Ihrig S. P., Schwaar T., Schmidt B. M., Hecht S.: A photoswitchable catalyst system for remote-controlled (co)polymerization in situ. Nature Catalysis, 1, 516-522 (2018). https://doi.org/10.1038/s41929-018-0091-8

[11] Schmidt S., Castiglione K., Kourist R.: Overcoming the incompatibility challenge in chemoenzymatic and multicatalytic cascade reactions. Chemistry-A European Journal, 24, 1755-1768 (2018).

https://doi.org/10.1002/chem.201703353

[12] Belluati A., Craciun I., Liu J., Palivan C. G.: Nanoscale enzymatic compartments in tandem support cascade reactions in vitro. Biomacromolecules, 19, 4023-4033 (2018).

https://doi.org/10.1021/acs.biomac.8b01019

[13] Wei W., Wu S., Shen X., Zhu M., Li S.: Nanoreactor with core-shell architectures used as spatiotemporal compartments for 'undisturbed' tandem catalysis. Journal of Inorganic and Organometallic Polymers and Materials, 29, 1235-1242 (2019).

https://doi.org/10.1007/s10904-019-01087-2
[14] Belluati A., Craciun I., Meyer C. E., Rigo S., Palivan C. G.: Enzymatic reactions in polymeric compartments: Nanotechnology meets nature. Current Opinion in Biotechnology, 60, 53-62 (2018). https://doi.org/10.1016/j.copbio.2018.12.011

[15] Zuo C., Wei W., Zhou Q., Wu S., Li S.: Artificial active nanoreactor with nature-Inspired sequential catalytic ability. ChemistrySelect, 2, 6149-6153 (2017). https://doi.org/10.1002/slct.201701014

[16] Zare M., Prabhakaran M. P., Parvin N., Ramakrishna S.: Thermally-induced two-way shape memory polymers: Mechanisms, structures, and applications. Chemical Engineering Journal, 374, 706-720 (2019). https://doi.org/10.1016/j.cej.2019.05.167

[17] Zheng X., Luo R., Zhu M., Li S.: Polymer nanoreactor with 'mobility-recalling' domains for on/off switchable catalysis. ChemCatChem, 7, 814-818 (2015). https://doi.org/10.1002/cetc.201402937

[18] Wei W., Zhou T., Wu S., Shen X., Zhu M., Li S.: An enzyme-like imprinted-polymer reactor with segregated quantum confinements for a tandem catalyst. RSC Advances, 8, 1610-1620 (2018). https://doi.org/10.1039/C7RA12320E

[19] Han Y., Yuan X., Zhu M., Li S., Whitcombe M., Piletsky S. A.: A catalytic and shape-memory polymer reactor. Advanced Functional Materials, 24, 4996-5001 (2014). https://doi.org/10.1002/adfm.201400768

[20] Zhou T., Zhu M., Wu S., Li S.: 'Online/offline'-shiftable imprinted polymer nanoreactor with selective/nonselective-switchable catalytic ability. Journal of Inorganic and Organometallic Polymers and Materials, 27, 21-30 (2017). https://doi.org/10.1007/s10904-016-0435-2

[21] Zhang X., Zhu M., Li S.: 'Key-vs.-lock'-like polymer reactor made of molecularly imprinted polymer containing metal nanoparticles. Journal of Inorganic and Organometallic Polymers and Materials, 24, 890-897 (2014). https://doi.org/10.1007/s10904-014-0061-9

[22] Li H., Niu Y.: Synthesis and characterization of amphiphilic block polymer poly(ethylene glycol)-poly (propylene carbonate)-poly(ethylene glycol) for drug delivery. Materials Science and Engineering C, 89, 160165 (2018). https://doi.org/10.1016/j.msec.2018.04.002

[23] Li S., Luo Y., Whitcombe M., Piletsky S. A.: A successive-reaction nanoreactor made of active molecularly imprinted polymer containing Ag nanoparticles. Journal of Materials Chemistry A, 1, 15102-15109 (2013). https://doi.org/10.1039/C3TA13454G

[24] Luo R., Zhu M., Shen X., Li S.: Polymer catalyst with self-assembled hierarchical access for sortable catalysis. Journal of Catalysis, 331, 49-56 (2015). https://doi.org/10.1016/j.jcat.2015.08.018 
[25] Wei W., Zhu M., Shen X., Wu S., Li S.: Switchable polymer reactor composed of mussel-inspired polymer that contains $\mathrm{Au}$ nanoparticles. RSC Advances, 6, 42869-42875 (2016).

https://doi.org/10.1039/C6RA04232E

[26] Li H., Sui L., Niu Y.: Synthesis of a carbon dioxidebased amphiphilic block copolymer and its evaluation as a nanodrug carrier. Journal of Materials Science, 53, 12718-12730 (2018).

https://doi.org/10.1007/s10853-018-2594-8

[27] Zheng Q., Niu Y., Li H.: Synthesis and characterization of imidacloprid microspheres for controlled drug release study. Reactive and Functional Polymers, 106, 99-104 (2016).

https://doi.org/10.1016/j.reactfunctpolym.2016.07.006

[28] Khanum H., Ullah K., Murtaza G., Khan S. A.: Fabrication and in vitro characterization of HPMC-g-poly (AMPS) hydrogels loaded with loxoprofen sodium. International Journal of Biological Macromolecules, 120, 1624-1631 (2018).

https://doi.org/10.1016/j.ijbiomac.2018.09.184
[29] Wu Y., Yang Y., Zhang Z., Wang Z., Zhao Y., Sun L.: A facile method to prepare size-tunable silver nanoparticles and its antibacterial mechanism. Advanced Powder Technology, 29, 407-415 (2018). https://doi.org/10.1016/j.apt.2017.11.028

[30] Qiao P., Sun B., Li H., Pan K., Tian G., Wang L., Zhou W.: Surface plasmon resonance-enhanced visible-NIRdriven photocatalytic and photothermal catalytic performance by $\mathrm{Ag} /$ mesoporous black $\mathrm{TiO}_{2}$ Nanotube Heterojunctions. Chemistry-An Asian Journal, 14, 177-186 (2019). https://doi.org/10.1002/asia.201801428

[31] Luo R., Zhu M., Yuan X., Li S.: An autonomic and 'offon-off'-switchable polymer microreactor. RSC Advances, 5, 5598-5603 (2015). https://doi.org/10.1039/C4RA14895A 